\title{
Impact of the architecture of dye sensitized solar cell-powered electrochromic devices on their photovoltaic performance and the ability to color change
}

\author{
Cláudia Costa, Dzmitry Ivanou, Jorge Pinto, Joaquim Mendes, Adélio Mendes* \\ LEPABE, Faculty of Engineering, University of Porto, 4200-465 Porto, Portugal
}

\section{A R T I C L E I N F O}

\section{Keywords:}

Smart windows

Photoelectrochromic device

Electrochromic solar cell

Tungsten oxide

\begin{abstract}
A B S T R A C T
The functional layers arrangement in a dye sensitized solar cell electrochromic device (DSSC-EC) on the energy conversion efficiency and on the ability to change the color is studied. The highest power conversion efficiency of $c a$. 7\% and good color change in closed circuit conditions was observed with electrochromic $\mathrm{WO}_{3}$ deposited on the counter-electrode of the DSSC. When $\mathrm{WO}_{3}$ layer was applied over the photoanode, the DSSC-EC displayed less power conversion efficiency $-3.4 \%$, but a more intense color change was observed under illumination and opened external circuit.

Response of the photocurrent vs. applied potential, incident photon-to-current conversion efficiency and optical behavior of the DSSC-EC were assessed and discussed considering optical properties of the components of the device and their energy bands alignment. Smart window and self-powered proof-of-concept pixelated device operating on DSSC-EC are presented.
\end{abstract}

\section{Introduction}

An electrochromic device (ECD) is a multi-layer electrochemical system containing at least one functional material (electrochrome) that changes color upon a reversible redox process. To obtain such effect, a device with two electrodes separated by an electrolyte should be built. The electrochromic layer should be in direct contact with an electrode for allowing electron flow (Gomes et al., 2016).

There are several possible applications for materials that can change color reversibly under the application of a low potential; one of the most important is smart windows. A smart window, name coined by Svensson and Granqvist (1985), has the ability of changing the light transmittance, which can be accomplished using an electrochromic device. Another very interesting application is information displays; these devices consist of a patterned electrochromic film deposited on a white pigment surface. They present an excellent contrast and a reading angle higher than displays with liquid crystals (Monk et al., 2007).

A photoelectrochromic device (PECD) is self-powered and changes spontaneously color when illuminated. Smart windows in buildings using this technology are able to improve indoor comfort by attenuating glare and undesired solar gains (Lampert, 2003). Smart windows can be also used in automotive and aeronautic industries and on helmets (Monk et al., 2007), where the choice of a PECD for the dynamic solar control with no external wiring is important.

When a dye sensitized solar cell (DSSC) is used combined with an electrochromic material the resulting device is named as DSSC-EC. DSSCs show very attractive advantages like, low-cost construct materials, conversion of direct and diffuse light and transparency (O'Regan and Grätzel, 1991). DSSC uses a photoelectrode made of a mesoporous layer of nanometer size $\mathrm{TiO}_{2}$ particles and attached to its surface is a monolayer of dye responsible for light absorption. Upon light absorption dye injects an electron into the conduction band of the semiconductor percolating it until the electrical contact. The oxidized sensitizer is regenerated by a redox couple, which in turn receives the electrons from the counter-electrode. In a DSSC-EC the electrochromic material is deposited on the working electrode or on the counter electrode of a DSSC (Wu et al., 2012; Deb, 2008). Electrochromic materials can be organic or inorganic and its choice depends on the architecture used, since the energy levels of the combined materials dictate the electron path through the device (Krašovec et al., 2004), the oxidized/ reduced colors and color contrast, ageing stability and price; in this work a layer of tungsten oxide was used. $\mathrm{WO}_{3}$ is a well-known electrochromic material. Along with viologens, it has been commercially explored on electrochromic applications such as "smart windows" (Baetens et al., 2010; Niklasson and Granqvist, 2007; Rauh, 1999). Popularity of $\mathrm{WO}_{3}$ stems from its strong color contrast (from

\footnotetext{
* Corresponding author.

E-mail address: mendes@fe.up.pt (A. Mendes).
} 
transparent to blue) with a relatively low production cost. $\mathrm{WO}_{3}$ has transitions both in the near infrared and visible region of the light spectrum, filtering thus a part of the solar light (Costa et al., 2012).

The first DSSC-EC device reported in 1996 (Bechinger et al., 1996) used $\mathrm{WO}_{3}$. It consists of an integrated photoelectrochromic device, instead of coupling a solar energy harvesting device followed by a full electrochromic device in a sequential arrangement (Benson and Branz, 1995; Bullock et al., 1996). This work focused on a simple architecture where one electrode was from a DSSC device and the other electrode was from an EC device combined by a liquid electrolyte; a transmittance variation of $17 \%$ was reported. DSSC-EC device where the electrochromic $\mathrm{WO}_{3}$ layer was applied over the TCO glass substrate, under the $\mathrm{TiO}_{2}$ photoelectrode was presented (Hauch et al., 2001). The color contrast obtained was good (transmittance variation of 40\%) but no solar to electricity conversion efficiency was reported. More recently (Cannavale et al., 2014) described a micropatterned bifunctional counter-electrode made of platinum layer stripes intercalated with $\mathrm{WO}_{3}$ over ITO layer stripes; both types of stripes were not electrically connected. The platinum and $\mathrm{WO}_{3}$ strips were then electrically connected to the photoelectrode through different electric circuits. When the platinum circuit is connected, the cell displayed PV function, while when the $\mathrm{WO}_{3}$ circuit is connected, the cell change color displaying an electrochromic function; this complex cell displayed a conversion energy efficiency of $c a .3 \%$ and the transmittance variation was $c a .25 \%$.

In the present work, $\mathrm{WO}_{3}$ was deposited on the photoelectrode (before and after the $\mathrm{TiO}_{2}$ layer) and on the counter electrode (on the top of the platinum layer) - Fig. $1 . \mathrm{WO}_{3}$ changes color upon reduction from transparent to blue, giving normally transparent devices (Costa et al., 2016). Solar light to electricity conversion efficiency of $c a$. 7\% was obtained with excellent color contrast. Two different architectures were used to produce DSSC-EC proofs of concepts of a pixilated device and of a smart window with a photoelectrode frame.

\section{Experimental}

\subsection{EC-DSSC device preparation}

FTO glass (TCO22-7, $2.2 \mathrm{~mm}$ thickness, $7 \Omega$ /square, Solaronix, Switzerland) adequately cleaned was used to make the photo- and counter-electrodes. FTO glass substrates were immersed into a $40 \mathrm{mM}$ aqueous $\mathrm{TiCl}_{4}$ (Titanium (IV) Chloride, 99.99\%, Acros Organic) solution at $70{ }^{\circ} \mathrm{C}$ for $20 \mathrm{~min}$, washed with ethanol and dried with $\mathrm{N}_{2}$. A layer of $\mathrm{TiO}_{2}$ paste (Ti-Nanoxide T/SP, Solaronix) was coated on the FTO glass by screen-printing, kept at room temperature for $20 \mathrm{~min}$ and then dried for $5 \mathrm{~min}$ at $120^{\circ} \mathrm{C}$. The screen-printing procedure was repeated two more times to reach a thickness of $12 \mu \mathrm{m}$ of $\mathrm{TiO}_{2}$ paste $\left(0.2 \mathrm{~cm}^{2}\right.$ of circular active area). After drying the films at $120^{\circ} \mathrm{C}$, they were gradually heated $\left(10^{\circ} \mathrm{C} / \mathrm{min}\right)$ up to $475^{\circ} \mathrm{C}$ and left at this temperature for $30 \mathrm{~min}$. After cooling to room temperature, the $\mathrm{TiO}_{2}$ electrodes were immersed into a $1 \mathrm{mM}$ ruthenizer 535-bisTBA dye in ethanol and kept at room temperature for $12 \mathrm{~h}$. To prepare the counter electrodes, two holes were drilled on the FTO glass using a drill with diamond tip. $\mathrm{WO}_{3}$ solution was prepared as described elsewhere (Costa et al., 2012) and it was deposited by spray casting and then sintered at $400{ }^{\circ} \mathrm{C}$ for $10 \mathrm{~min}$; $\mathrm{WO}_{3}$ was deposited on the platinum layer, on the $\mathrm{TiO}_{2}$ layer and under it - Fig. 1.

The sensitized $\mathrm{TiO}_{2}$ electrodes and counter-electrodes were assembled into a sandwich type cell and sealed with a hot-melt gasket of $25 \mu \mathrm{m}$ thickness - Surlyn ${ }^{\circledast}$ (Meltonix 1170-25, Solaronix) by hotpressing. The electrolyte was injected into the cell through the holes made in the counter-electrode. Electrolyte AN 50 (Solaronix) was used. Lithium iodide was added to the electrolyte in a mass fraction of $8 \%$ (Costa et al., 2016).

The holes were then covered with a Surlyn ${ }^{\circledR}$ film and a lamella glass and sealed with a soldering iron. To ensure good electrical contacts in the electrochemical measurements, the edges of the FTO outside of the cell were painted with silver paint.

\subsection{Photoelectrochemical characterization}

A $150 \mathrm{~W}$ xenon light source (Oriel class A simulator, Newport USA) irradiating $100 \mathrm{~mW} \cdot \mathrm{cm}^{-2}$ at the surface of the EC-DSSC device and equipped with an air mass filter of 1.5 (Newport, USA) was used. I-V curves were recorded using an electrochemical workstation (Zahner). Average of five measurements is presented. Deviation in a series of measurements was not exceed 1\%; the deviation in parameters of the devices was not exceed $5 \%$ in the batch.

\subsection{IPCE and optical characterizations}

The incident-photon-to-electron conversion efficiency (IPCE) spectra were recorded using a PC- operated setup consisting of a $300 \mathrm{~W}$ Xenon lamp as a light source (Newport 66902), a monochromator (Newport Cornerstone 74125), a Lock-in amplifier (Newport Merlin 70104), set of optical filters and a light chopper operated at frequency of $8.3 \mathrm{~Hz}$. The incident photon flux was normalized using a calibrated silicon detector (Newport 70356). The bias light was supplied by a $100 \mathrm{~W}$ halogen lamp, and the light intensity was adjusted to 0.3 Sun by the driven current from a constant current source. Measurements were typically made at $3 \mathrm{~nm}$ wavelength intervals between 300 and $800 \mathrm{~nm}$. Absorbance spectra of DSSC-EC devices were recorded using the same equipment. Samples were placed between the output of monochromator and Si detector. Incident light flux was equal to 1 sun. The response from Si detector without DSSC-EC device between monochromator and detector was taking as reference.

\section{Results and discussion}

Electrochromic material $\mathrm{WO}_{3}$ was chosen because its stability when inserted in a DSSC device, namely because its stability to UV light. This characteristic along with its transparent oxidized state and high color contrast made it a very interesting candidate for smart windows and displays applications. Color change of $\mathrm{WO}_{3}$ follows the redox reaction (Mohapatra, 1978):

$\mathrm{WO}_{3}$ (s, transparent) $+x \mathrm{Li}^{+}$(aq) $+\mathrm{e}^{-} \leftrightarrow \mathrm{Lix} \mathrm{WO}_{3}$ (s, blue)

Among other cations $\mathrm{Li}^{+}$was shown to be the best one to compensate the charge in the reduced form of $\mathrm{WO}_{3}$ (Monk et al., 2007). Therefor it was added to the AN-50 electrolyte of the DSSC-EC. In previous reports (Costa et al., 2016), LiI at a mass fraction of $8 \%$ is indicated to have the highest performance; this salt and concentration is also used in this work.

\subsection{Device architecture}

Fig. 1 illustrates the three architectures assessed; the $\mathrm{WO}_{3}$ layer was deposited on the top of the platinum layer, at the counter-electrode (Fig. 1a), at the photoelectrode between the TCO and the $\mathrm{TiO}_{2}$ layers (Fig. 1b) and at the photoelectrode, on top of the $\mathrm{TiO}_{2}$ layer (Fig. 1c). The energy levels in these three architectures $\left(\mathrm{TiO}_{2}\right.$ and dye (Chung et al., 2012), $\mathrm{WO}_{3}$ (Bera et al., 2010) and electrolyte (Maçaira et al., 2015)) are also shown in Fig. 1.

\subsection{Photovoltaic performance}

Fig. 2 and Table 1 show the $I-V$ characteristic curves and the performing parameters of the devices: the open circuit potential, $V_{\mathrm{OC}}$, the short circuit current density, $J_{\mathrm{SC}}$, the fill factor, $F F$, and the energy conversion efficiency, $\eta$. The device named " $\mathrm{WO}_{3} / \mathrm{Pt}$ " refers to the architecture represented in Fig. $1 \mathrm{a}$; " $\mathrm{WO}_{3} / \mathrm{TiO}_{2}$ " is the architecture represented in Fig. $1 \mathrm{~b}$ and " $\mathrm{TiO}_{2} / \mathrm{WO}_{3}$ " is the architecture represented in 

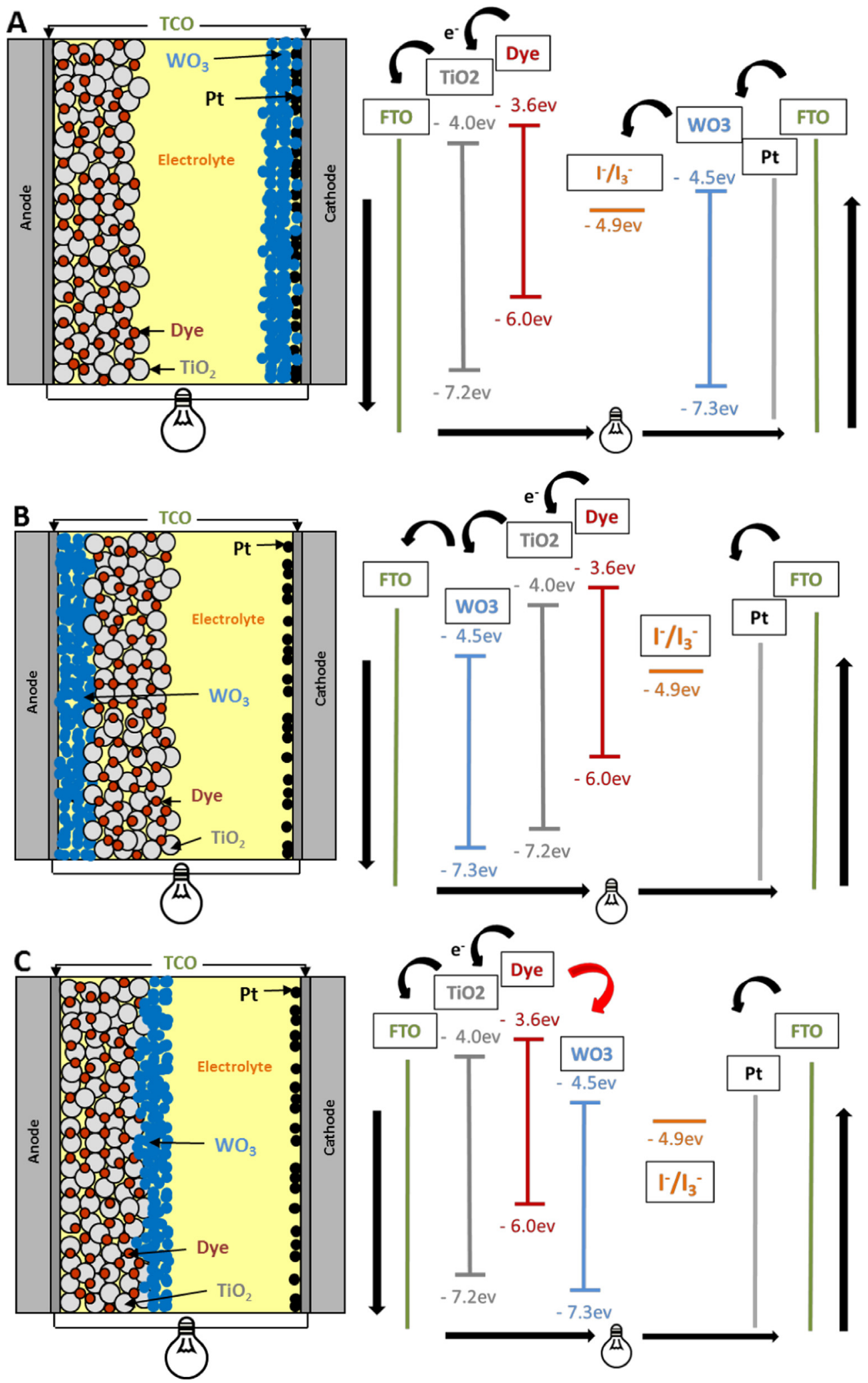

Fig. 1. Variations performed to the architecture of the device and their energy diagrams. Between $\mathrm{TiO}_{2} / \mathrm{FTO}$, between $\mathrm{WO}_{3} / \mathrm{FTO}$ and between $\mathrm{FTO} / \mathrm{Pt}$ is an ohmic contact.

Fig. 1c. Configuration $\mathrm{WO}_{3} / \mathrm{Pt}$ allows the best energy conversion efficiency. Architecture $\mathrm{TiO}_{2} / \mathrm{WO}_{3}$ shows lower $V_{O C}$ and $J_{\mathrm{SC}}$, and architecture $\mathrm{WO}_{3} / \mathrm{TiO}_{2}$ shows the lowest energy performance.

Configuration $\mathrm{WO}_{3} / \mathrm{Pt}$ should perform mostly as a DSS; the $\mathrm{WO}_{3}$ mesoporous layer easily permeates the redox species, which reduce at the platinum layer and oxidize at the dye. Compared with the previous configuration, electrons in configuration $\mathrm{WO}_{3} / \mathrm{TiO}_{2}$ lose $c a .0 .5 \mathrm{~V}$ when crossing from the $\mathrm{TiO}_{2}$ to the $\mathrm{WO}_{3}$ layers and the photoactive layer receives less light, which is partially absorbed in the $\mathrm{WO}_{3}$ layer. Since $\mathrm{WO}_{3}$ is in contact with the electrolyte $\mathrm{WO}_{3}$ nanoparticles do not adsorb 


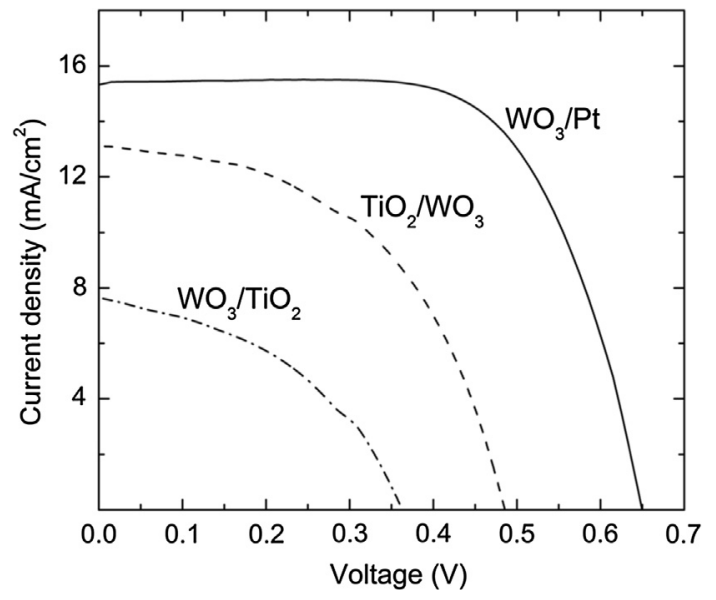

Fig. 2. $I-V$ curves of DSSC-EC devices with different architectures.

Table 1

Photovoltaic parameters of the DSSC-EC with different architectures.

\begin{tabular}{llll}
\hline & $\mathrm{WO}_{3} / \mathrm{TiO}_{2} \ldots$ & $\mathrm{TiO}_{2} / \mathrm{WO}_{3} \ldots$ & $\ldots \mathrm{WO}{ }_{3} / \mathrm{Pt}$ \\
\hline$V o c(\mathrm{~V})$ & 0.36 & 0.49 & 0.65 \\
$J \mathrm{sc}\left(\mathrm{mA} / \mathrm{cm}^{2}\right)$ & 7.63 & 13.15 & 14.79 \\
$F F$ & 0.43 & 0.51 & 0.66 \\
$\eta(\%)$ & 1.25 & 3.41 & 6.93 \\
\hline
\end{tabular}

N719 dye), recombination should take place. Moreover, the $\mathrm{I}_{3}{ }^{-}$ions formed diffuse back towards the photoelectrode where the recombination increases (Boschloo and Hagfeldt, 2009). This configuration displays the poorest energy performance. The path of the injected electron in configuration $\mathrm{TiO}_{2} / \mathrm{WO}_{3}$ is similar to a conventional DSSC, except that the injected electron can move forward to the $\mathrm{TiO}_{2}$ photoelectrode but also backward to the $\mathrm{WO}_{3}$ layer, originating recombination with the electrolyte though not as severe as in configuration $\mathrm{WO}_{3}$ / $\mathrm{TiO}_{2}$. This configuration shows then an intermediated energy conversion performance.

\subsection{IPCE}

The $I-V$ response in Fig. 2 is the result of a combined electrochemical response from all electrochemically active components $\left(\mathrm{TiO}_{2}\right.$, $\mathrm{WO}_{3}$, dye) of DSSC-EC devices. IPCE spectroscopy allows analyzing the contribution of each component to the photocurrent. Fig. 3 depicts the IPCE spectra of the three DSSC-EC architectures. Three plainly

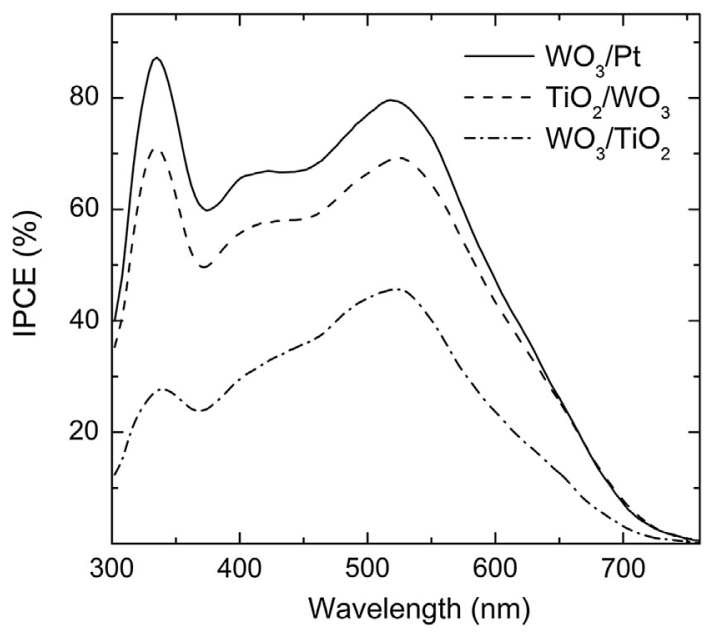

Fig. 3. IPCE spectra of DSSC-EC devices with different architectures. distinguishable signals are observed: at $300-375 \mathrm{~nm}, 375-460 \mathrm{~nm}$ and $460-750 \mathrm{~nm}$ ranges. The edge in IPCE plots at $375 \mathrm{~nm}(3.3 \mathrm{eV})$ fits well with the effective band gap of anatase (3.2 eV) (Landmann et al., 2012). Photocurrents at wavelengths less $375 \mathrm{~nm}$ correspond to excitation of $\mathrm{TiO}_{2}$. The edge at $460 \mathrm{~nm}(2.7 \mathrm{eV})$ could be associated with photoelectron generation in $\mathrm{WO}_{3}(2.6-2.8 \mathrm{eV}$ (González-Borrero et al., 2010). Photocurrents at wavelengths above $460 \mathrm{~nm}$ with maximum value at $525 \mathrm{~nm}$ are originated from excitation of N719 dye, which has an absorption peak at $530 \mathrm{~nm}$ (De Angelis et al., 2011). In a general way, IPCE spectra are in good agreement with $I-V$ curves. The device $\mathrm{WO}_{3} / \mathrm{Pt}$ shows the best quantum efficiency. In this case the energy level of $\mathrm{WO}_{3}$ and all other components of DSSC-ES device are well positioned, i.e. no barriers are formed for electron percolation (Fig. 1a). Photocurrent efficiency of configuration $\mathrm{TiO}_{2} / \mathrm{WO}_{3}$ is slightly smaller than that of configuration $\mathrm{WO}_{3} / \mathrm{Pt}$. This small decrease of IPCE observed in whole spectral region, however, causes a drastic drop of the overall efficiency (Table 1). $\mathrm{As}_{\mathrm{WO}_{3}}$ has a band gap energy $2.6-2.8 \mathrm{eV}$ it acts as an optic filter on the way of light towards $\mathrm{TiO}_{2}$ in configuration $\mathrm{WO}_{3} / \mathrm{TiO}_{2}$. Sensitized photocurrents (in $460-750 \mathrm{~nm}$ region) are also smaller.

\subsection{Optical properties of DSSC-EC}

The three DSSC-EC configurations were studied regarding the color change. To obtain a spontaneous stronger color change in configuration $\mathrm{WO}_{3} / \mathrm{Pt}$, the electrolyte would need to be added with a mass fraction less than $8 \%$ of LiI. In the present work, the electrolyte used in the three configurations was the same (AN 50 with $8 \%$ of mass fraction of LiI) therefore the spontaneous color change from transparent to blue in configuration $\mathrm{WO}_{3} / \mathrm{Pt}$ under light and at short-circuit is inhibited. The electrolyte composition in configurations $\mathrm{WO}_{3} / \mathrm{TiO}_{2}$ and $\mathrm{TiO}_{2} / \mathrm{WO}_{3}$ is adequate for the spontaneous color change from transparent to blue at open-circuit and under illumination.

Fig. 4 shows the change in absorbance at $750 \mathrm{~nm}$ of the three DSSCEC configurations. The operating conditions considered are: (a) dark and open circuit; (b) dark and short-circuit; (c) light (0.3 sun) and open circuit and; (d) light ( 0.3 sun) and short-circuit. For the three configurations, the color did not change in dark. Configurations $\mathrm{WO}_{3} / \mathrm{TiO}_{2}$ and $\mathrm{TiO}_{2} / \mathrm{WO}_{3}$ under light and open-circuit exhibited a spontaneous color change and when at short-circuit they become mostly colorless. It is also apparent that the device with the lowest solar to electricity conversion efficiency $\left(\mathrm{WO}_{3} / \mathrm{TiO}_{2}\right)$ presents also the least color contrast; this should be assigned to the smaller current density available for reducing the $\mathrm{WO}_{3}$ layer. Configuration $\mathrm{WO}_{3} / \mathrm{Pt}$ displayed an opposite color change effect.

From these experiments, it can be concluded that only configurations $\mathrm{WO}_{3} / \mathrm{Pt}$ and $\mathrm{TiO}_{2} / \mathrm{WO}_{3}$ should be used for practical applications depending on if the colored configuration is required at $\mathrm{ON}$ or OFF positions.

\section{Technological considerations}

Two different architectures were used to fabricate DSSC-EC proofs of concepts of a pixilated device (configuration $\mathrm{TiO}_{2} / \mathrm{WO}_{3}$ ) and of a smart window with a photoelectrode frame (configuration $\mathrm{WO}_{3} / \mathrm{Pt}$ ).

\subsection{Pixilated device}

Fig. 5 shows the scheme of the DSSC-EC proof of concept $\left(60 \mathrm{~cm}^{2}\right)$ with 9 pixels - sub-module - isolated electrically at the photoelectrode but with a common counter-electrode. The electrochromic $\mathrm{WO}_{3}$ layer was deposited covering and exciding the area of the photoelectrode (configuration $\mathrm{TiO}_{2} / \mathrm{WO}_{3}$ ), defining individual pixels. The electrochromic $\mathrm{WO}_{3}$ layer is colorless at short-circuit (ON). When illuminated, the $\mathrm{WO}_{3}$ spontaneously changes color from transparent to blue.

Once the electrolyte is yellow (because of the iodide) the resulting color of the $\mathrm{WO}_{3}$ layer is green, as shown in Fig. 6. Under light and 


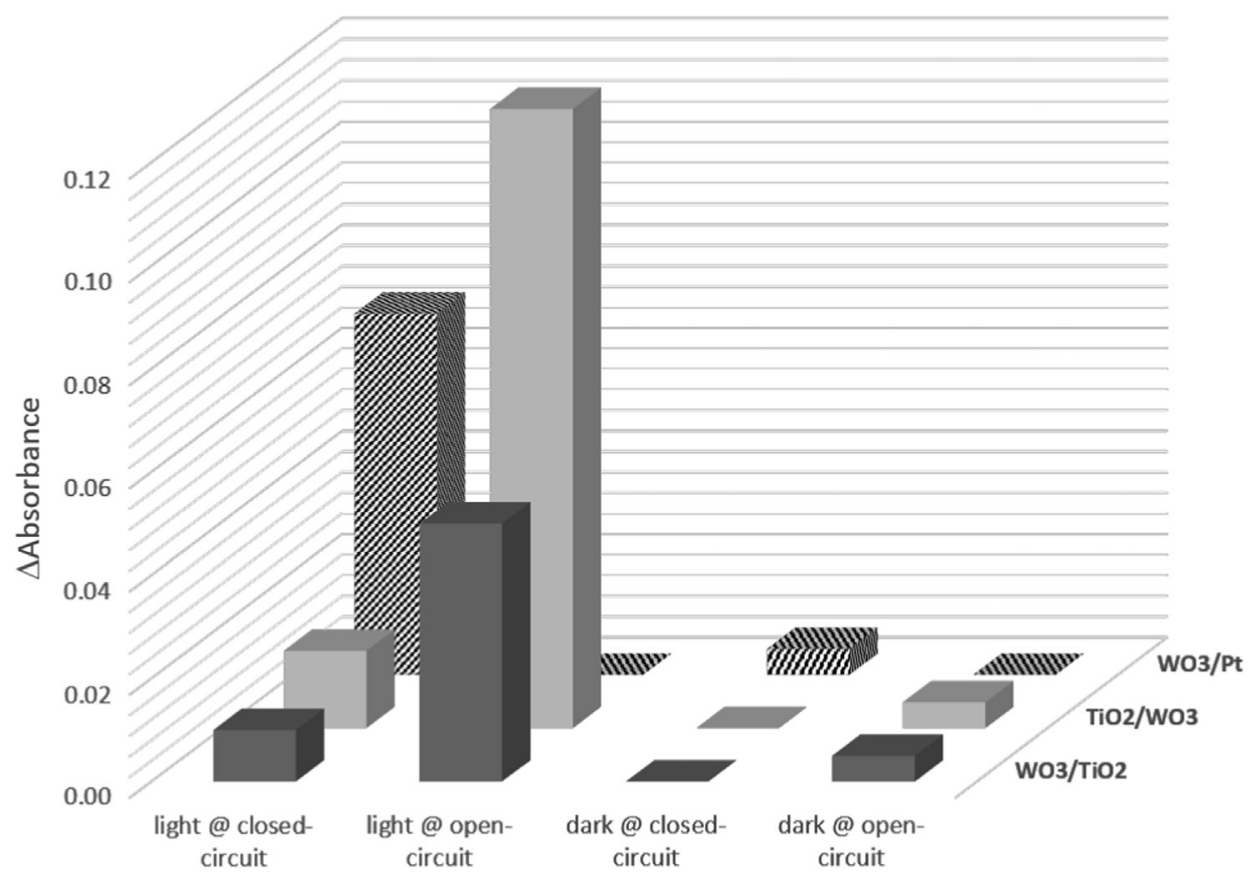

Fig. 4. Absorbance variation obtained for DSSC-EC devices in several conditions.

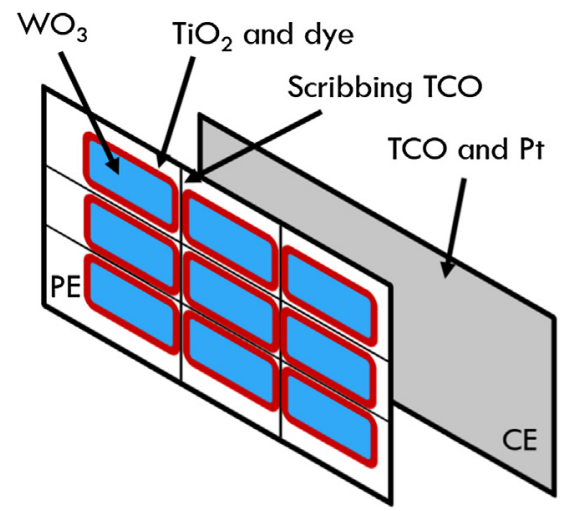

Fig. 5. Scheme of the DSSC-EC proof of concept $\left(60 \mathrm{~cm}^{2}\right)$ with 9 pixels isolated electrically at the photoelectrode and with a common counter-electrode.

short-circuit, the $\mathrm{WO}_{3}$ layer becomes transparent and the resulting color yellow (electrolyte).

An electronic circuit, Fig. 7a, was added to the sub-module to control individually each pixel. The switching circuit (SC) allows shortcircuiting the parallel resistors changing the working point of the corresponding pixel between ON (short circuit mode) to OFF (maximum power point mode) - Fig. 7b. The circuit in Fig. $7 \mathrm{a}$ and $\mathrm{c}$ has been implemented on a veroboard, where ' + ' connects to the cell cathode and connectors f1...f9 connect to the anode of the respective pixel.

The nomination of resistors was calculated based on the $I-V$ curve obtained just after the device construction (obtained at 0.9 sun). The power curve and equivalent load resistance were determined; the maximum power point (MPP) was observed at $0.25 \mathrm{~V}$, which corresponds to apply an equivalent load of $c a$. $75 \Omega$. Then, under 1.2 sun illumination the short circuit and MPP currents were obtained for each pixel - Table $2-$ as well as the power of all in-series connected pixels at MPP condition $-3.7 \mathrm{~mW}$. The switch has an internal resistance $(\approx 2 \Omega)$ that result in a non-null potential drop across the switch.

The maximum power generated by the DSSC-EC sub-module was determined as $3.7 \mathrm{~mW}$.

Fig. 8 shows a series of $I-V$ curves as a function of time during $500 \mathrm{~h}$ of the DSSC-EC sub-module. It can be seen that the DSSC-EC sub-
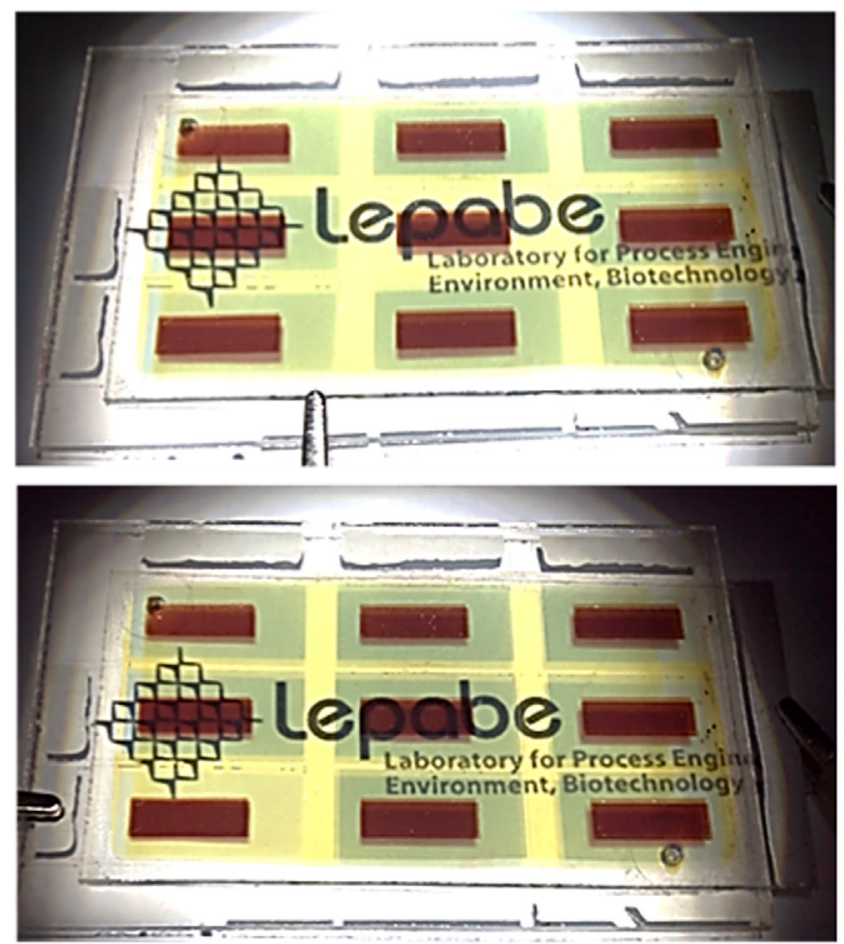

Fig. 6. Pixel device with $\mathrm{WO}_{3}$ deposited on the photoelectrode (configuration $\mathrm{TiO}_{2} / \mathrm{WO}_{3}$ ).

module is quite stable.

\subsection{Smart window}

A smart window proof of concept using electrochromic PEDOT:PSS (poly (3,4-ethylenedioxythiophene) polystyrene sulfonate) applied as counter-electrode in a DSSC-EC cell was recently reported (Costa et al., 2016). The use of an inorganic electrochromic material instead of an organic is expected to increase the durability of the device especially under $\mathrm{UV}$ radiation. In this work configuration $\mathrm{WO}_{3} / \mathrm{Pt}$ was used with a 


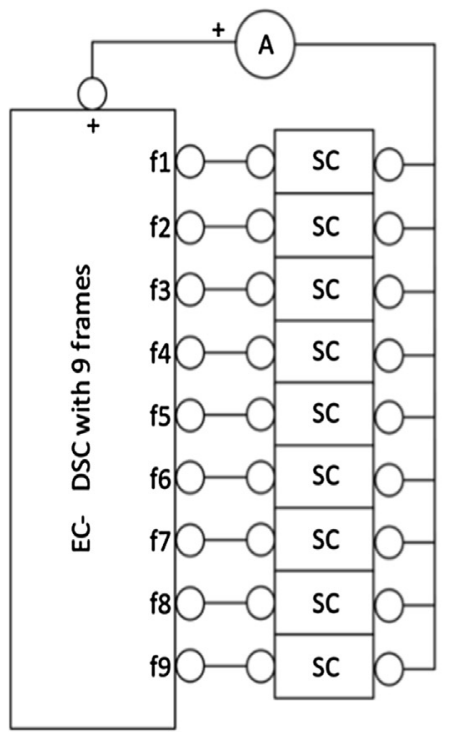

a) Circuit diagram

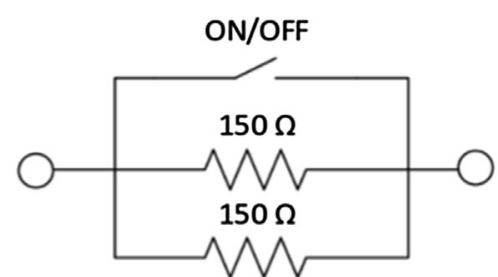

b) Switching circuit (SC)

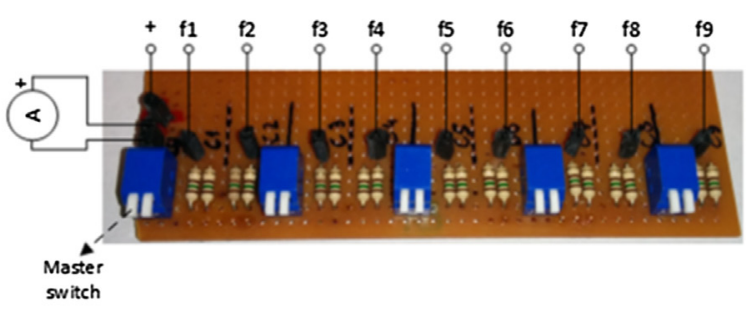

c) Circuit

Fig. 7. Circuit for evaluation of the 9 pixel DSSC-EC.

Table 2

Potential differences and currents for short circuit and MPP test of individual pixels.

\begin{tabular}{lllll}
\hline Pixel & Short circuit $(\mathrm{V})$ & Short circuit $(\mathrm{mA})$ & MPP $(\mathrm{V})$ & MPP $(\mathrm{mA})$ \\
\hline f1 & 0.011 & 5.38 & 0.21 & 3.85 \\
f2 & 0.011 & 5.66 & 0.21 & 3.80 \\
f3 & 0.011 & 6.70 & 0.29 & 4.26 \\
f4 & 0.011 & 5.27 & 0.18 & 3.46 \\
f5 & 0.011 & 4.33 & 0.13 & 2.58 \\
f6 & 0.011 & 4.80 & 0.19 & 2.82 \\
f7 & 0.011 & 5.85 & 0.21 & 3.64 \\
f8 & 0.011 & 5.25 & 0.19 & 3.10 \\
f9 & 0.011 & 6.10 & 0.28 & 3.78 \\
\hline
\end{tabular}

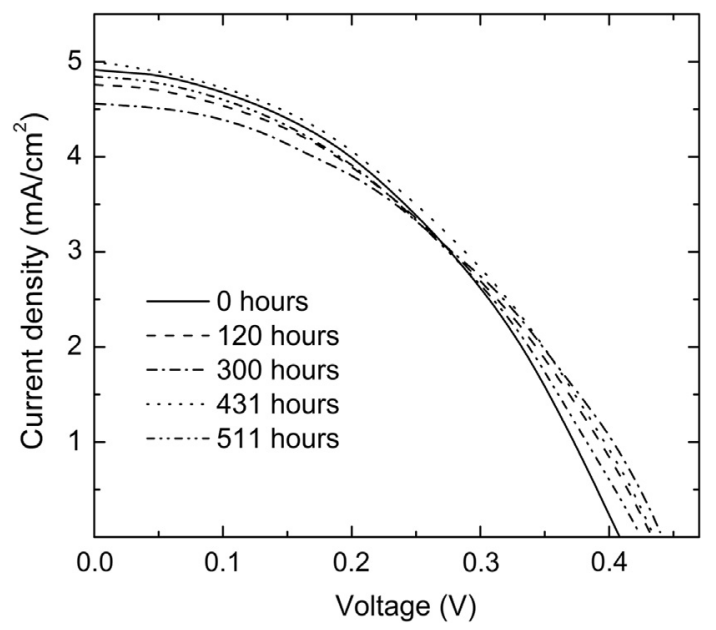

Fig. 8. $I-V$ curves at different instants of DSSC-EC pixel device aged for $500 \mathrm{~h}$ under constant 0.6 sun illumination at $65^{\circ} \mathrm{C}$

synthetic electrolyte (with 5\% mass fraction of LiI and propylene carbonate as solvent). The sealing process is also critical for the long-term stability of the device and the present study employs laser-assisted glass sealing (Ivanou et al., 2016). Fig. 9 shows the final aspect of the device in both color states and the color changes to blue spontaneously when

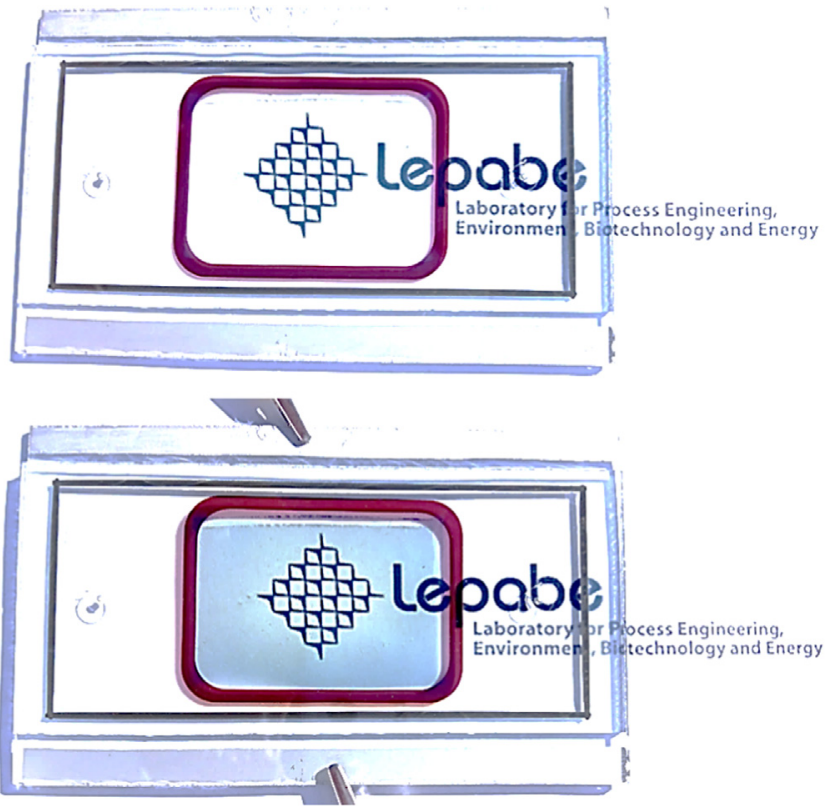

Fig. 9. Smart window with configuration $\mathrm{WO}_{3} / \mathrm{Pt}$ and laser-assisted sealed using a glass frit in oxidized (above) and reduced (below) states.

sort-circuited.

In this configuration the yellow color of the electrolyte is not apparent since iodide is present in a much smaller concentration. The developed $\mathrm{WO}_{3} / \mathrm{Pt}$ glass sealed DSSC-EC demonstrated to fulfill the target objectives of a smart window to control the income of sunlight. The device is self-powered and to reduces the income irradiance of up to $c a .25 \%$ (transmittance). This same cell design could be used to fabricate a self-powered, low cost, low energy consumption display as illustrated in Fig. 10.

\section{Conclusions}

Three different architectures of DSSC-EC devices were studied using $\mathrm{WO}_{3}$ as electrochromic material. The $\mathrm{WO}_{3}$ layer was deposited on top of 


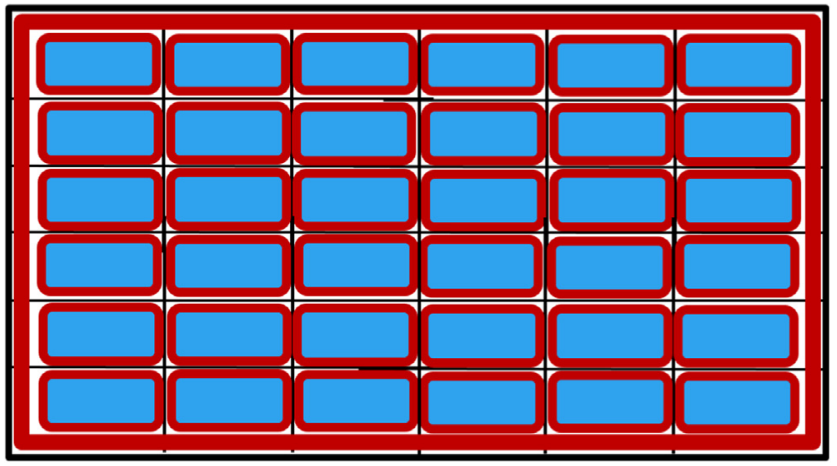

Fig. 10. Scheme of a DSSC-EC proof of concept self-powered display based on a DSSC-EC with photovoltaic frames around pixels.

the platinum layer, at the counter-electrode $\left(\mathrm{WO}_{3} / \mathrm{Pt}\right)$, at the photoelectrode between the TCO and the $\mathrm{TiO}_{2}$ layers $\left(\mathrm{WO}_{3} / \mathrm{TiO}_{2}\right)$ and at the photoelectrode, on top of the $\mathrm{TiO}_{2}$ layer $\left(\mathrm{TiO}_{2} / \mathrm{WO}_{3}\right)$. Configuration $\mathrm{WO}_{3} / \mathrm{Pt}$ allowed the best energy conversion efficiency (6.9\%). Architecture $\mathrm{TiO}_{2} / \mathrm{WO}_{3}$ showed lower $V_{O C}$ and $J_{\mathrm{SC}}$ (conversion efficiency of $3.4 \%$ ) and architecture $\mathrm{WO}_{3} / \mathrm{TiO}_{2}$ showed the lowest energy performance (conversion efficiency of $1.3 \%$ ). Configurations $\mathrm{WO}_{3} / \mathrm{TiO}_{2}$ and $\mathrm{TiO}_{2} / \mathrm{WO}_{3}$ under illumination and open-circuit showed spontaneous color change from colorless to light blue. It is also apparent that the device with the lowest solar to electricity conversion efficiency $\left(\mathrm{WO}_{3} / \mathrm{TiO}_{2}\right)$ presents the least color contrast.

A proof of concept of a DSSC-EC self-powered display was built implementing the $\mathrm{TiO}_{2} / \mathrm{WO}_{3}$ configuration. Also, a self-powered smart window, implementing the $\mathrm{WO}_{3} / \mathrm{Pt}$ DSSC-EC configuration, laser-assisted glass sealed, was built. Both devices proved to be quite stable and to perform as required. Since the DSSC-EC device implementing the $\mathrm{WO}_{3} / \mathrm{Pt}$ configuration used a colorless electrolyte, the color contrast was greater and the device more aesthetic, appropriate for using in a smart window to control the income solar illumination or as a low-cost, self-powered display.

\section{Acknowledgments}

This work was financially supported by: Project POCI-01-0145FEDER-006939 (Laboratory for Process Engineering, Environment, Biotechnology and Energy - LEPABE funded by FEDER funds through COMPETE2020 - Programa Operacional Competitividade e Internacionalização (POCI) - and by national funds through FCT Fundação para a Ciência e a Tecnologia; and by the European Commission through the Seventh Framework Programme, the Specific Programme "Ideas" of the European Research Council for research and technological development as part of an Advanced Grant under grant agreement N. 321315 .

\section{References}

Baetens, R., Jelle, B.P., Gustavsen, A., 2010. Properties, requirements and possibilities of smart windows for dynamic daylight and solar energy control in buildings: A state-ofthe-art review. Sol. Energy Mater. Sol. Cells 94, 87-105.

Bechinger, C., Ferrere, S., Zaban, A., Sprague, J., Gregg, B.A., 1996. Photoelectrochromic windows and displays. Nature 383, 608-610.

Benson, D.K., Branz, H.M., 1995. Design goals and challenges for a photovoltaic-powered electrochromic window covering. Sol. Energy Mater. Sol. Cells 39, 203-211.

Bera, D., Qian, L., Tseng, T.K., Holloway, P.H., 2010. Quantum dots and their multimodal applications: A review. Materials (Basel) 3, 2260-2345.

Boschloo, G., Hagfeldt, A., 2009. Characteristics of the iodide/triiodide redox mediator in dye-sensitized solar cells. Acc. Chem. Res. 42, 1819-1826.

Bullock, J.N., Bechinger, C., Benson, D.K., Branz, H.M., 1996. Semi-transparent a-SiC: H solar cells for self-powered photovoltaic-electrochromic devices. J. Non. Cryst. Solids 198-200, 1163-1167.

Cannavale, A., Manca, M., De Marco, L., Grisorio, R., Carallo, S., Suranna, G.P., Gigli, G., 2014. Photovoltachromic device with a micropatterned bifunctional counter electrode. ACS Appl. Mater. Interfaces 6, 2415-2422.

Chung, I., Lee, B., He, J., Chang, R.P.H., Kanatzidis, M.G., 2012. All-solid-state dye-sensitized solar cells with high efficiency. Nature 485, 486-489.

Costa, C., Mesquita, I., Andrade, L., Mendes, A., 2016. Photoelectrochromic devices: Influence of device architecture and electrolyte composition. Electrochim. Acta 219, 99-106.

Costa, C., Pinheiro, C., Henriques, I., Laia, C.A.T., 2012. Inkjet printing of sol-gel synthesized hydrated tungsten oxide nanoparticles for flexible electrochromic devices. ACS Appl. Mater. Interfaces 4, 1330-1340.

De Angelis, F., Fantacci, S., Mosconi, E., Nazeeruddin, M.K., Grätzel, M., 2011. Absorption spectra and excited state energy levels of the N719 dye on $\mathrm{TiO}_{2}$ in dye-sensitized solar cell models. J. Phys. Chem. C 115, 8825-8831.

Deb, S.K., 2008. Opportunities and challenges in science and technology of $\mathrm{WO}_{3}$ for electrochromic and related applications. Sol. Energy Mater. Sol. Cells 92, 245-258.

Gomes, L., Branco, A., Moreira, T., Feliciano, F., Pinheiro, C., Costa, C., 2016. Increasing the electrical conductivity of electrochromic PEDOT:PSS films - A comparative study. Sol. Energy Mater. Sol. Cells 144, 631-640.

González-Borrero, P.P., Sato, F., Medina, A.N., Baesso, M.L., Bento, A.C., Baldissera, G., Persson, C., Niklasson, G.A., Granqvist, C.G., Ferreira Da Silva, A., 2010. Optical band-gap determination of nanostructured $\mathrm{WO}_{3}$ film. Appl. Phys. Lett. 96061909.

Hauch, A., Georg, A., Baumgärtner, S., Opara Krašovec, U., Orel, B., 2001. New photoelectrochromic device. Electrochim. Acta 46, 2131-2136.

Ivanou, D.K., Santos, R., Maçaira, J., Andrade, L., Mendes, A., 2016. Laser assisted glass frit sealing for production large area DSCs panels. Sol. Energy 135, 674-681.

Krašovec, U.O., Georg, A., Georg, A., Wittwer, V., Luther, J., Topič, M., 2004. Performance of a solid-state photoelectrochromic device. Sol. Energy Mater. Sol. Cells 84, 369-380.

Lampert, C.M., 2003. Large-area smart glass and integrated photovoltaics. Sol. Energy Mater. Sol. Cells 76, 489-499.

Landmann, M., Rauls, E., Schmidt, W.G., 2012. The electronic structure and optical response of rutile, anatase and brookite $\mathrm{TiO}_{2}$. J. Phys. Condens. Matter 24195503.

Maçaira, J., Mesquita, I., Andrade, L., Mendes, A., 2015. Role of temperature in the recombination reaction on dye-sensitized solar cells. Phys. Chem. Chem. Phys. 17, 22699-22710.

Mohapatra, S.K., 1978. Electrochromism in $\mathrm{Li}_{\mathbf{x}} \mathrm{WO}_{3}$. J. Electrochem. Soc. 125, 284-288.

Monk, P.M.S., Mortimer, R.J., Rosseinsky, D.R., 2007. Electrochromism and Electrochromic Devices. Cambridge University Press.

Niklasson, G.A., Granqvist, C.G., 2007. Electrochromics for smart windows: Thin films of tungsten oxide and nickel oxide, and devices based on these. J. Mater. Chem. 17, $127-156$.

O'Regan, B., Grätzel, M., 1991. A low-cost, high-efficiency solar cell based on dye-sensitized colloidal $\mathrm{TiO}_{2}$ films. Nature 353, 737-740.

Rauh, R.D., 1999. Electrochromic windows: an overview. Electrochim. Acta 44, 3165-3176.

Svensson, J.S.E.M., Granqvist, C.G., 1985. Electrochromic coatings for "smart windows". Sol. Energy Mater. 12, 391-402.

Wu, C.H., Hsu, C.Y., Huang, K.C., Nien, P.C., Lin, J.T., Ho, K.C., 2012. A photoelectrochromic device based on gel electrolyte with a fast switching rate. Sol. Energy Mater. Sol. Cells 99, 148-153. 